\title{
The Risk Assessment and Clinical Research of Bile Duct Injury After Transcatheter Arterial Chemoembolization for Hepatocellular Carcinoma
}

\author{
Houyun $X u^{\prime}$ \\ Xiping $\mathrm{Yu}^{2}$ \\ Jibo $\mathrm{Hu}^{\prime}$ \\ 'Department of Radiology, The Fourth \\ Affiliated Hospital, Zhejiang University \\ School of Medicine, Yiwu, People's \\ Republic of China; ${ }^{2}$ Department of \\ Pathology, The Fourth Affiliated Hospital, \\ Zhejiang University School of Medicine, \\ Yiwu,People's Republic of China
}

Purpose: To retrospectively evaluate the risk factors and the clinical outcomes of bile duct injury after transcatheter arterial chemoembolization (TACE) for hepatocellular carcinoma (HCC) and to evaluate factors that aid clinical detection and subsequent treatment of the injured bile duct.

Materials and Methods: All patients undergoing TACE for HCC were retrospectively reviewed for identification of bile duct injury. The clinical spectrum of all the patients analyzed including patients' demographics, laboratory data, radiologic imaging and mode of treatment.

Results: From January 2015 to December 2017, a total of 21 patients (4.3\%) out of 483 patients with 693 TACE procedures were identified to have bile duct injury at our single institution. There were 17 males and 4 females, with a mean age of $59.8 \pm 11.6$ years (range 34-84). About $14.3 \%$ (3/21) patients show the high-density shadow around the bile duct wall in one week non-enhanced CT, and 76.2\% (16/21) cases ALP $>200 \mathrm{U} / \mathrm{L}$, all these patients showed bile duct injury on the subsequent follow-up CT. Post-TACE follow-up blood biochemistry showed that alanine aminotransferase (ALT), aspartate aminotransferase (AST), alkaline phosphatase (ALP) and gamma glutamyl transpeptidase (GGT) increased significantly compared with pre-TACE level. The incidence of various types of bile duct injuries on CT was intrahepatic bile duct dilatation (57.1\%), biloma $(25.7 \%)$ and hepatic hilar biliary strictures $(17.1 \%)$, respectively. Patients with prior hepatectomy as well as proximal arterial chemoembolization carried a higher risk of post-TACE bile duct injury in terms of microvascular damage to the peribiliary capillary plexus.

Conclusion: Bile duct injury complicating TACE is not caused by a single factor, but by a variety of factors, and is closely related to the microvascular compromise of the bile ducts and subsequent chronic biliary infection. Lipiodol deposited along the bile duct wall and the sharp rise of ALP $>200 \mathrm{U} / \mathrm{L}$ in one week after TACE can predict bile duct injury and early intervention may prevent the occurrence of serious complications. The probability of bile duct injury in patients with prior hepatectomy and proximal arterial chemoembolization increases significantly.

Keywords: hepatocellular carcinoma, transcatheter arterial chemoembolization, complications, bile duct injury, biloma

\section{Introduction}

Hepatocellular carcinoma is the second most frequent cause of cancer-related death worldwide. There will be an estimated 18.1 million new cancer cases and 9.6 million cancer deaths in 2018. ${ }^{1}$ Many patients present with unresectable hepatocellular carcinoma and transcatheter arterial chemoembolization (TACE) is a widely practiced procedure in 
intermediate BCLC stage B hepatocellular carcinoma (HCC) as well as in the palliative treatment of metastatic cancer of the liver, supported by level 1 evidence. ${ }^{2-4}$ TACE is generally well tolerated and besides the frequent occurrence of postembolization syndrome (transient abdominal pain, fever, nausea, vomiting, malaise and related laboratory changes), TACE-related complications occur infrequently. These include upper gastrointestinal hemorrhage, liver failure, renal function impairment, biloma, hepatic abscess, pulmonary embolism, embolic cholecystitis. ${ }^{5-8}$ As a serious complication of TACE, bile duct injury has been reported with an average incidence of $0.5 \%$ to $4 \% .{ }^{9-13}$ The pathophysiology, risk factors, imaging manifestation and clinical implications of the bile duct injuries have been reported, ${ }^{10-14,19-28}$ although rarely involved in the prediction of bile duct injury (Supplementary Table 1). So through this retrospective cohort analysis, we have analyzed the incidence, predictive and risk factors, meanwhile provided recommendations for clinical investigation and treatment of bile duct injuries.

\section{Materials and Methods}

The records of all patients undergoing TACE treatments from January 2015 - December 2017 were reviewed. The study was conducted in accordance with the Declaration of Helsinki (as revised in 2013) and was approved by the Committee on Human Subject Research and Ethics of The Fourth Affiliated Hospital of Zhejiang University School of Medicine. Written informed consent was waived in this retrospective study because the personal information of patients was anonymized prior to analyses. We confirmed the confidentiality of patients' data and compliance with the Declaration of Helsinki (as revised in 2013).

Inclusion criteria ${ }^{16,17}$ for patient identification were TACE as the sole non-operative treatment in patients with an underlying diagnosis of HCC confirmed by pathology, by typical imaging findings on CT and/or MRI (characteristic nodular enhancement in the arterial-phase images and washout in the delayed-phase images and by hyper-vascularity and a nodular stain on hepatic angiography.

Exclusion criteria: ${ }^{14,15}$ Other locoregional treatments, mixed HCC-cholangiocarcinoma, HCC invading the biliary system, prior hepatobiliary surgery, biliary drainage or sphincter of Oddi violation.

Bile duct injuries were identified by evaluation of MRI or CT post procedure.

Patient demographics, laboratory data, radiologic imaging and mode of treatment were recorded for all identified patients.
Table I 2 I patients, Profile of Bile Duct Injury

\begin{tabular}{|l|r|}
\hline Patient Character & $\mathbf{n}(\%)$ \\
\hline Male & I7 (8I\%) \\
\hline Female & $4(19 \%)$ \\
\hline Mean age (year) & $59.8 \pm 11.6$ \\
\hline Liver cirrhosis & \\
HBV related & $15(71.4 \%)$ \\
HCV related & $1(4.8 \%)$ \\
Schistosoma related & $1(4.8 \%)$ \\
Etiology unknown & $4(19 \%)$ \\
\hline Child-Pugh classification & \\
A & $18(85.7 \%)$ \\
B & $3(14.3 \%)$ \\
C & $0(0 \%)$ \\
\hline Underlying disease & \\
Hypertension & 2 \\
Diabetes & 3 \\
Hypertension and diabetes & 1 \\
Thrombotic disease & 2 \\
None & 13 \\
\hline
\end{tabular}

A total of 21 patients with biliary complications were therefore included and analyzed. Relevant patient information is shown in Table 1. Baseline characteristics of 483 patients with or without bile duct injury in Table 2.

\section{Data Records}

Patient profiles consisted of age, gender, comorbid diseases (hypertension and diabetes), Child-Pugh classification and etiology of liver cirrhosis (viral, alcoholic or otherwise) as well as prior surgical history if any. Biochemical data included alkaline phosphatase (ALP), gamma glutamyl transpeptidase (GGT), aspartate aminotransferase (AST), alanine aminotransferase (ALT), $\alpha$-Fetoprotein (AFP), total bilirubin, direct bilirubin and serum albumin. Pertinent TACE-related datasets included tumor burden (diameter and number of nodules), chemotherapeutic regimens with or without the use of gelatin sponge or PVA particles, embolization site, TACE frequency, outcome and treatment of bile duct injury. Medical imaging studies were predominantly contrast-enhanced CT and/ or MRI.

\section{TACE Procedure}

Written informed consent was obtained from each patient before TACE. 
Table 2 Baseline Characteristics of Patients with or without Bile Duct Injury

\begin{tabular}{|c|c|c|c|}
\hline Patient Character & $\begin{array}{l}\text { With Bile } \\
\text { Duct Injury } \\
\quad(n=2 I)\end{array}$ & $\begin{array}{l}\text { Without Bile } \\
\text { Duct Injury } \\
\quad(n=462)\end{array}$ & $\mathbf{P}$ \\
\hline $\begin{array}{l}\text { Gender } \\
\text { Male } \\
\text { Female }\end{array}$ & $\begin{array}{c}17(81 \%) \\
4(19 \%)\end{array}$ & $\begin{array}{c}393(85 \%) \\
69(15 \%)\end{array}$ & 0.84 \\
\hline Mean age (year) & $59.8 \pm 11.6$ & $61.6 \pm 12.3$ & 0.48 \\
\hline $\begin{array}{l}\text { Liver cirrhosis } \\
\text { HBV related } \\
\text { HCV related } \\
\text { Alcohol related } \\
\text { Schistosoma } \\
\text { related } \\
\text { Etiology unknown }\end{array}$ & $\begin{array}{c}15(71.4 \%) \\
1(4.8 \%) \\
0(0 \%) \\
1(4.8 \%) \\
4(19 \%)\end{array}$ & $\begin{array}{c}300(64.9 \%) \\
14(3 \%) \\
116(25.1 \%) \\
23(5 \%) \\
9(1.9 \%)\end{array}$ & 0.000016 \\
\hline $\begin{array}{l}\text { Child-Pugh } \\
\text { classification } \\
\text { A } \\
\text { B } \\
\text { C }\end{array}$ & $\begin{array}{c}18(85.7 \%) \\
3(14.3 \%) \\
0(0 \%)\end{array}$ & $\begin{array}{c}346(74.9 \%) \\
116(25.1 \%) \\
0(0 \%)\end{array}$ & 0.26 \\
\hline $\begin{array}{l}\text { Underlying disease } \\
\text { Hypertension } \\
\text { Diabetes } \\
\text { Hypertension and } \\
\text { diabetes } \\
\text { Thrombotic } \\
\text { disease } \\
\text { None }\end{array}$ & $\begin{array}{l}2(9.5 \%) \\
13(61.9 \%)\end{array}$ & $\begin{array}{c}69(14.9 \%) \\
55(11.9 \%) \\
32(6.9 \%) \\
19(4.1 \%) \\
287(62.1 \%)\end{array}$ & 0.74 \\
\hline
\end{tabular}

Note: Except for the etiology of cirrhosis, all the other baseline characteristics have no statistical significance.

Patient exclusion criteria were: main portal vein tumor thrombus/thrombosis, hepatic/biliary infection, poor reserve liver function at Child-Pugh $\mathrm{C}$, platelet count $<50 \times 103$ ), renal dysfunction (serum creatinine $\geq 150$ $\mu \mathrm{mol} / \mathrm{L}$ ), allergy to contrast medium and iodine oil, concomitant other malignancy and pregnant women. ${ }^{17-20}$

Patients underwent TACE according to a standard protocol. The right/left common femoral artery was punctured using the Seldinger technique and a 5-F introducer sheath was inserted. A 5-F visceral catheter was engaged into the celiac trunk and superior mesenteric artery. After celiac and superior mesenteric arteriography, selective/superselective catheterisation of the artery feeding the tumor was performed with a 4-F visceral catheter or microcatheter in case needed. If patient presented with significant arterioportal or arteriovenous shunting, obliteration using appropriate embolic agents PVA (AngioDynamics Inc,
USA) or gelatin sponge particles (Gelfoam, Upjohn, Kalamazoo, MI) was mandatory. A mixture of the anticancer agent and Lipiodol (Andre Guerbet, Aulnay-sousBois, France) was infused in $10 \mathrm{~min}$. Under fluoroscopic control, followed by injection of a particulate embolic agent chosen by the interventional radiologist until complete stasis of all feeder arteries. The mixture was prepared just before injection by pumping to and fro 10 more times between two 50-mL syringes connected to each other via a 3-way stopcock. Depending upon the tumor vascularity and the dimension of HCC, the anticancer drugs were used Epirubicin (Kyowa Hakko, Tokyo, Japan) 10 to $50 \mathrm{mg}$ and Mitomycin C (Kyowa Hakko) 2 to $10 \mathrm{mg}$. The total amount of iodized oil was determined based on the tumor burden and vascularity, but did not exceed $20 \mathrm{~mL}$ in a single TACE session.

Preventive-TACE was defined in patients with previous hepatic resection history prior to TACE with no tumor staining identified at angiography. Proximal artery was defined including the proper hepatic artery, right and/or left hepatic artery.

\section{Follow-Up Protocol}

All patients underwent serial hepatic and renal function and complete blood count (CBC) check-up within 1-week of the procedure. Tumor marker was titrated regularly. Standard imaging post TACE was carried out; Nonenhanced CT was obtained at 1 week to detect wall thickening of bile duct and iodized oil deposition in the wall. Follow-up CT and MRI were carried out at 1-month, 2 3-month and 6-months. If local tumor recurrence or newly developed lesions were encountered during followup, an additional TACE session was conducted according to BCLC guidelines (Figure 1). CT and MRI images were interpreted by three experienced radiologists in separate session. A decision was made based on consensus. All patients were followed for at least 6 months after TACE.

\section{Imaging Criteria of Bile Duct Injury}

Bile duct was normal in all patients prior to TACE.

Bile duct injury induced by TACE ${ }^{20-27}$ was determined by the presence of one or more of the following; intrahepatic bile duct dilation (IBDD), biloma (BM) or hepatic hilar bile duct strictures (HBDS).

IBDD was defined as: disproportionately dilated bile ducts in lobar or segmental distribution along the Glisson's sheath, with or without surrounding hyperemia. HBDS was defined where MRCP or MRI images depicting filling 


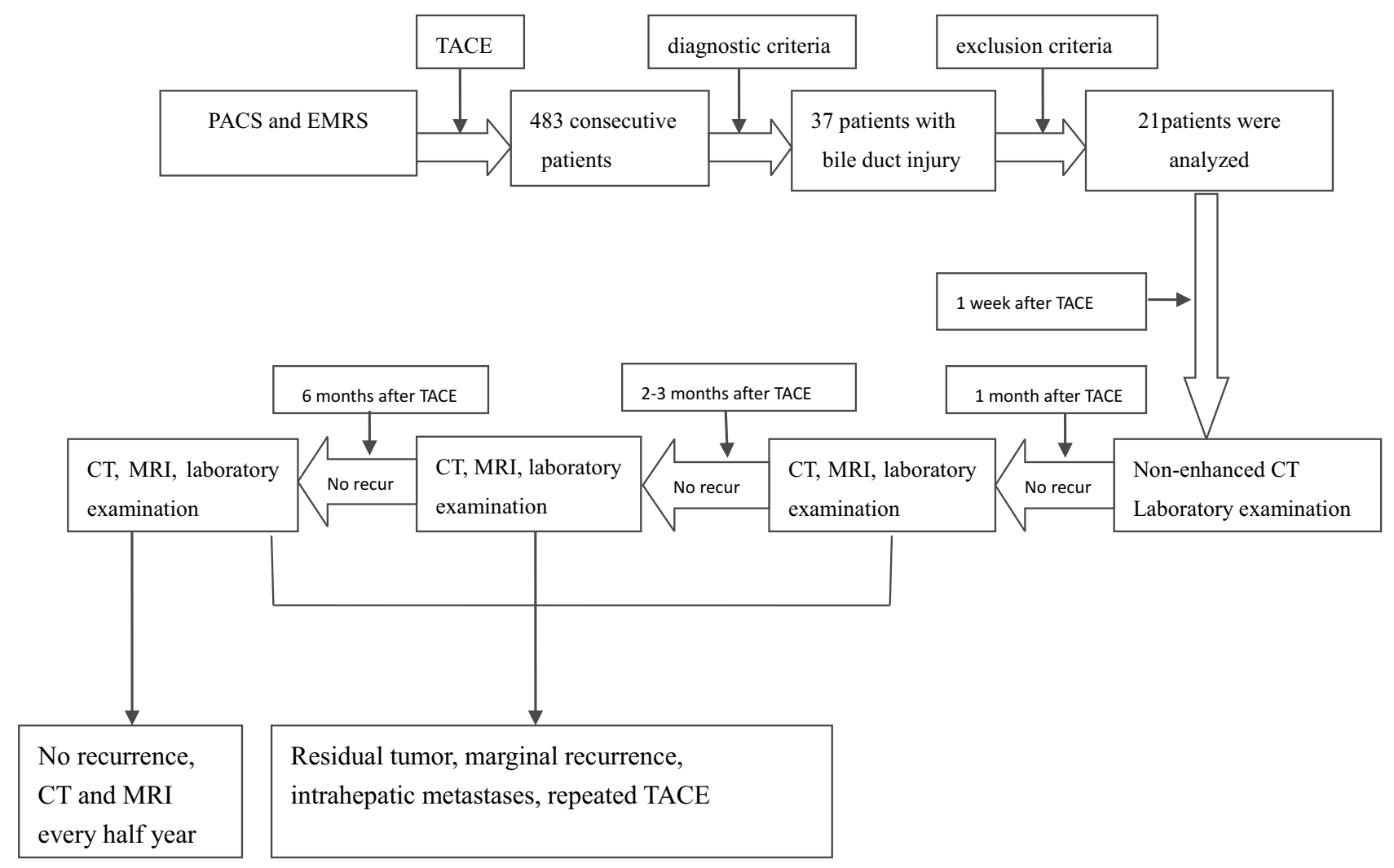

Figure I Flow Chart of CT and MRI follow-up after TACE.

Abbreviations: PACS, picture archiving and communication systems; EMRS, electronic medical record system; TACE, transcatheter arterial chemoembolisation; No recur, no recurrence; $\mathrm{CT}$, computed tomography; MRI, magnetic resonance imaging.

defects appearance, or varying degrees of hilar bile duct strictures with or without proximal bile duct dilation.

$\mathrm{BM}$ was diagnosed when at least one of the following signs were seen on follow-up CT or MRI: solitary or multiple round cystic lesions with or without segmental bile duct dilatation; a subcapsular fluid collection of hypoattenuating density on CT or a high signal intensity similar to bile duct on T2WI MRI.

The diagnosis of bile duct injuries had been validated by multidisciplinary team physicians in view of comprehensive evaluation of imaging features, laboratory data and clinical manifestation of conflicted patients. ${ }^{28,29}$

\section{Statistical Analysis}

Categorical variables were described using percentages. Continuous variables were expressed as means and standard deviations. Comparisons between the two groups were made using chi-square test or Fisher's exact test for categorical variables and a two-sided $t$-test or Wilcoxon rank sum test as appropriate for continuous variables. Comparisons between multi-groups were made upon analysis of variance (ANOVA) or non- parametric test. ${ }^{30}$ Multivariate logistic regression analyses were used to identify risk and predictive factors of bile duct injury. All analyses were performed using SPSS software version 22.0 (IBM Corporation, College Station, TX, USA) and Python software version 3.0. A p-value below 0.05 was considered statistically significant.

\section{Results}

From January 2015 to December 2017, a total of 483 patients received 693 consecutive TACE-procedures for $\mathrm{HCC}$ at a single institution. Patients received between one and six treatments, with the average number of treatments per patient being 1.43. Retrospective analysis of pre-TACE and post-TACE CT studies with enhancement (483 vs 1293), Enhanced-MRI studies pre-TACE and post-TACE (452 vs 1123), medical history and laboratory data, identified 37 patients with evidence of bile duct injury. In these 37 patients the following were excluded from further analysis. Other local regional therapies: post-TACE radiofrequency ablation $(n=1)$, alcohol ablation $(n=4)$, cryoablation 
$(n=2)$, implantation of radioiodine-125 particle $(n=1)$. HCC invading bile duct $(n=1)$, HCC invading portal vein $(n=2)$. History of previous biliary-enteric surgery or biliary intervention: biliary-enteric anastomosis $(\mathrm{n}=1)$, percutaneous transhepatic biliary drainage (PTBD, $\mathrm{n}=1$ ), endoscopic retrograde cholangiopancreatography (ERCP, $n=1)$. Patient lost to follow-up or pertinent data inaccessible $(n=2)$

A total of 21 cases with bile duct injury were identified. All the clinical data and pertinent information of the patients were summarized in Supplementary Table 2.

\section{Patients}

There were 410 males and 73 females, with a mean age of $61.5 \pm 12.1$ years. There was a significant difference in incidence between men and women. The functional status of the liver was Child A in 364 and Child B in 119 For the 483 patients, $4.37 \%$ (8/183) patients of bile duct injury had comorbid diseases including diabetes, hypertension and lower extremity deep vein thrombosis. As compared to the $4.33 \%$ (13/300) patients with no comorbid disease, there is no statistical significance $(\mathrm{P}=0.985)$. The average HCC tumor diameter was smaller in the 21 patients with bile duct injury than in the 483 patients without bile duct injury $(3.15 \pm 4.19 \mathrm{~cm}$ vs 4.86 $\pm 3.18 \mathrm{~cm}, \mathrm{p}=0.076)$. Interestingly, we found $8 \%(16 /$ 200) patients with prior hepatectomy had bile duct injury after TACE (Preventive-TACE) while only 1.8\% $(5 / 283)$ of those without prior hepatectomy did. Therefore, we believed that prior hepatectomy history might predict significantly higher probability of bile duct injuries.

\section{TACE Protocols}

All 21 cases of bile duct injury were treated using a similar TACE protocol. The average dose of lipiodol was $7.2 \pm 3.3 \mathrm{~mL}$, range between 3 and $20 \mathrm{~mL}$. A total of 48 TACE procedures were carried out in 21 patients after surgery, with target embolization artery of proper hepatic artery $(n=14)$, left hepatic artery $(n=3)$, right hepatic artery $(n=10)$, left and right hepatic artery $(n=9)$ and subsegmental artery branch $(n=12)$. The corresponding site of bile duct injury was in the right lobe $(n=7)$, left lobe $(n=2)$, left and right lobes $(n=11)$ and hepatic hilum $(n=6)$. The location of bile duct injury and the siting of the arteries embolized were highly consistent (Table 3).
There were no statistically significant differences in the chemotherapeutic drug dose or lipiodol dose in 21 patients. There were 3 patients embolized with PVA particles $(500-700 \mu \mathrm{m})$ and/or gelatin sponge and the average onset of bile duct injury following TACE was $1.67 \pm 1.65$ months. In the other 18 patients embolized solely using iodized oil and the interval between treatment and injury was $4 \pm 3.34$ months (independent-samples $t$ test, $\mathrm{p}=0.049$ ). It seemed likely that combination use of PVA and gelatin sponge may accelerate the process of bile duct injuries. However, there is no statistical significance compared the PVA particles and/or gelatin sponge group with the iodized oil group for the 483 patients $(\mathrm{p}=0.387)$.

\section{$\mathrm{CT}$ and MRI Findings}

All 21 patients depicted various degrees of IBDD, BM and HBDS. In the first week after the first TACE, non-enhanced CT revealed a small amount of iodized oil deposited in the wall of right intrahepatic bile duct in 3 patients $(14.3 \%, 3 / 21)$, which in turn became apparent right intrahepatic bile duct dilatation and biloma at 3.5 months follow-up (Figure 2), compared with non-bile duct injury group $(1.1 \%, 5 / 462)$, there was significant statistical difference $(\chi 2=21.498$, $\mathrm{P}=0.000$ ) (Tables 7 and 8). The area under the curve (AUC $=0.815$ ) for the predictor of bile duct injury after TACE made it possible to discriminate between patients with bile duct injury and those without (Figure 6). Most IBDD displayed no apparent progress on late follow-up

Table 3 Relationship Between the Site of Embolization and Location of Bile Duct Injury

\begin{tabular}{|c|c|c|}
\hline $\begin{array}{l}\text { Embolization Level } \\
\text { (48) }\end{array}$ & $\begin{array}{l}\text { No. of Bile Duct } \\
\text { Injury(35) }\end{array}$ & $\begin{array}{l}\text { Location of Bile Duct } \\
\text { Injury }\end{array}$ \\
\hline Tumor-feeding artery(12) & 9 & $\begin{array}{l}\text { Close to the tumor } \\
\text { location=7 } \\
\text { Disclose to the tumor } \\
\text { location=2 }\end{array}$ \\
\hline Proximal embolization (36) & 26 & \\
\hline Right hepatic artery $(10)$ & 7 & $\begin{array}{l}\text { Segment } 5=2 \\
\text { Segment } 6=3 \\
\text { Segment } 7=0 \\
\text { Segment } 8=2\end{array}$ \\
\hline Left hepatic artery(3) & 2 & $\begin{array}{l}\text { Segment } 1=0 \\
\text { Segment } 2=1 \\
\text { Segment } 3=0 \\
\text { Segment } 4=1\end{array}$ \\
\hline $\begin{array}{l}\text { Right and left hepatic } \\
\text { arteries }(9)\end{array}$ & 8 & Left and right lobe $=8$ \\
\hline Proper hepatic artery $(14)$ & 9 & $\begin{array}{l}\text { Hepatic hilar }=6 \\
\text { Left and right lobe }=3\end{array}$ \\
\hline
\end{tabular}



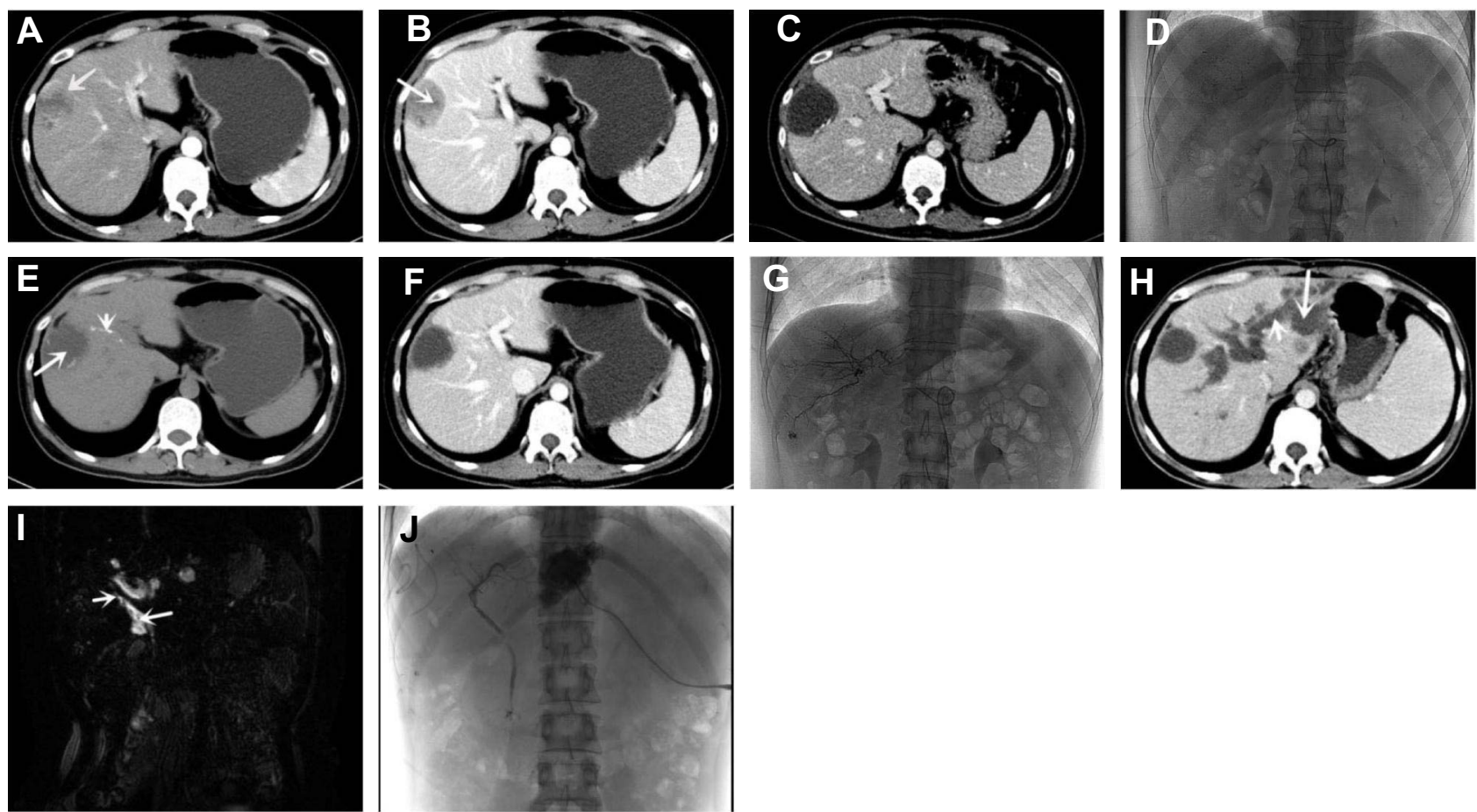

Figure 2 A 34 years old man presented with right upper quadrant discomfort (the $4^{\text {th }}$ patient). (A and B) Enhanced CT showed characteristic nodular enhancement on the arterial-phase (arrow) and washout on the delayed-phase images (arrow), consistent with HCC diagnosis. (C) After HCC resection, enhanced CT venous phase depicted a local low density lesion, which was defined as postoperative changes. (D) After the first TACE, iodine oil deposited mostly in the liver parenchyma and scantily in the intravascular spaces. (E and F) One month later, non-enhanced CT demonstrated a little iodine oil accumulating in the RHD (short arrow), circular density attenuation area without enhancement was defined as postoperative changes (long arrow). (G) After the second TACE, most iodine oil retained in the hepatic artery and minimal in the hepatic parenchyma. In the segment 6, a nodular staining indicated a hemangioma. $(\mathbf{H})$ Two months later, enhanced CT denoted visible intrahepatic bile ducts dilation (short arrow) and biloma formation (long arrow). (I) MRCP depicted proximal CBD dilation (long arrow) and hilar bile ducts strictures (short arrow). (J) PTC demonstrated coarse wall and discernible filling defects in CBD.

Abbreviations: CBD, common bile duct; TACE, transcatheter arterial chemoembolization; HCC, hepatocellular carcinoma; RHD, right hepatic duct; PTC, percutaneous transhepatic cholangiography; MRCP, magnetic resonance cholangiopancreatography.

imaging except in 3 patients, biloma insidiously developed (Figure 3). In 6 patients with HBDS, MRCP depicted prominent filling defects in hilar bile ducts, 4 patients did not improve after PTCD, whereas the remaining 2 patients, remarkable recovery with medical treatment and PTCD were observed. Besides, CT and MRI imaging in the later follow-up appreciated additional hepatobiliary abnormalities: gallbladder stones $(n=2)$, intrahepatic bile duct stones $(\mathrm{n}=2)$ (Figure 4), and liver atrophy with portal vein stenosis $(n=5)$, including right hepatic lobe atrophy $(n=4)$ and left hepatic lobe atrophy $(\mathrm{n}=1)$ (Figure 5).

\section{Types and Risk Factors of Bile Duct Injury}

The incidence of TACE-induced biliary duct injury was 4.3\% (21/483), including 3 cases showed IBDD, BM and HBDS, 3 cases showed HBDS with IBDD, 5 cases showed BM with IBDD, 9 cases showed IBDD, and 1case showed BM. According to the type of bile duct injury classifying, IBDD 57.1\% (20/35), BM 25.7\% (9/ $35)$, and HBDS $17.1 \%(6 / 35)$. The average onset of bile duct injury was $3.9 \pm 2.7$ months, range $1-12$ months. We found intrahepatic bile duct dilatation was most common in comparison to hilar bile duct stricture and biloma, ( $\mathrm{p}=0.009$, Chi-square test). The incidence of intrahepatic bile duct dilatation was $88.9 \%$ (8/9) in biloma group and $33.2 \%(2 / 6)$ in HBDS group, suggesting the proportion of intrahepatic bile duct dilatation was significantly higher in biloma group than in the HBDS group ( $\mathrm{p}=0.047$, Fisher exact test). The incidence of intrahepatic bile duct injury including IBDD and BM was significantly higher than HBDS $(82.9 \%, 29 / 35$ vs $17.1 \%, 6 / 35)$, indicating the probability of intrahepatic bile duct injury was significantly increased as compared with HBDS ( $\mathrm{p}=0.000$, Chi-square test). We have performed logistic regression analyses to identify risk factors of bile duct injury for these 483 patients, finding that resection of liver tumor and proximal embolization have positive correlations with the bile duct injury, while tumor-feeding artery embolization shows a negative correlation (Tables 4 and 5). 

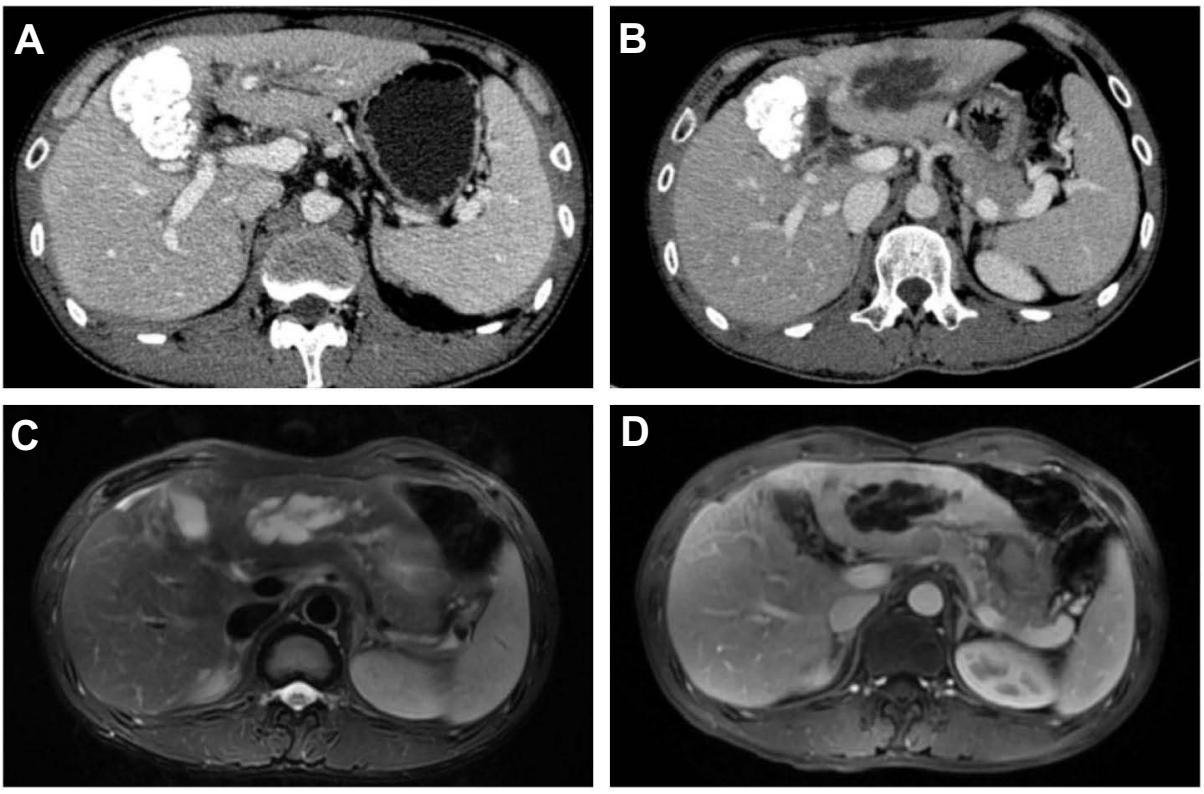

Figure 3 A 44-year-old man underwent TACE for HCC (the $5^{\text {th }}$ patient). (A) One month after TACE, enhanced-CT depicted mild dilatation of left intrahepatic bile duct and visible iodized oil deposition in the quadrate lobe. (B) 3 months after TACE, enhanced-CT demonstrated a round low density with no apparent enhancement in the left hepatic lobe, which was typical for a biloma formation. (C) Follow-up MRI T2WI denoted an ovoid high signal intensity lesion that was similar to the bile duct signal intensity in the same site. (D) Contrast enhanced MRI-TIWI revealed no apparent enhancement and the patient remained clinically asymptomatic.

Abbreviations: TACE, transcatheter arterial chemoembolization; HCC, hepatocellular carcinoma.

\section{Changes in Laboratory Data}

All laboratory data were summarized in Table 6. Except in two patients, AST and ALT were in the normal range before TACE $(\mathrm{AST}=38.6 \pm 28.2 \mu \mathrm{mol} / \mathrm{L}, \mathrm{ALT}=35.6 \pm$ $19.4 \mu \mathrm{mol} / \mathrm{L})$. The elevated liver enzyme in these two patients (AST: $122 \mu \mathrm{mol} / \mathrm{L}$ and $106 \mu \mathrm{mol} / \mathrm{L}$, respectively) was considered to be related to $\mathrm{HCC}$ and chronic B hepatitis (These two patients have no history of alcoholic liver disease, autoimmune liver disease, cholecystitis and cholelithiasis). The liver enzyme of AST and ALT showed significant difference pre-TACE and post-TACE $(38.6 \pm 28.2 \mu \mathrm{mol} / \mathrm{L}$ vs $63.67 \pm 29.3 \mu \mathrm{mol} / \mathrm{L}, \mathrm{p}=0.014 ; 35.6$ $\pm 19.4 \mu \mathrm{mol} / \mathrm{L}$ vs $65.2 \pm 42.9 \mu \mathrm{mol} / \mathrm{L}, \mathrm{p}=0.05$, respectively).

Pre-TACE ALP was slightly elevated in 3 cases, while in the remaining 18 cases were within normal limit (120.1 \pm $100.9 \mu \mathrm{mol} / \mathrm{L})$. The ALP level in post-TACE (249.1 $\pm 158.3 \mu \mathrm{mol} / \mathrm{L})$ was significantly higher than Pre-TACE. There were 16 patients $(76.2 \%, 16 / 21)$ with ALP $>200 \mathrm{U} /$ $\mathrm{L}$ in one week, and the difference was statistically significant compared with that of the non-bile duct injury group (2.2\%, 10/462) $(\chi 2=216.116, P=0.000)$ (Tables 7 and 8). Among them, 4 patients were complicated with biliary tract infection and one case with sepsis. The GGT level in the pre-TACE was normal $76.4 \pm 114.5 \mu \mathrm{mol} / \mathrm{L}(\mathrm{n}=19)$, whereas in the 2 patients the preoperative GGT was markedly elevated
$(442 \mu \mathrm{mol} / \mathrm{L}$ and $339 \mu \mathrm{mol} / \mathrm{L}$, respectively), HCC with coexisting fatty liver were presumed likely. Follow-up GGT level was increased significantly as compared with preTACE $\quad(342.7 \pm 318.4 \mu \mathrm{mol} / \mathrm{L} \quad$ vs $\quad 76.4 \pm 114.5 \mu \mathrm{mol} / \mathrm{L}$, $\mathrm{p}=0.003$ ). AFP, indirect bilirubin and serum albumin prior to TACE showed no significant differences compared with the post-TACE follow-up data. By comparing with preTACE data, a one-week-data after TACE and subsequent follow-up data (non-parametric test), we found that ALP and GGT had no significant differences between the data in one week and follow-up, but are significantly different from pre-TACE data in the 21 patients $(120.1 \pm 100.9 \mu \mathrm{mol} / \mathrm{L}$ vs $187.4 \pm 81.8 \mu \mathrm{mol} / \mathrm{L}$ vs $249.1 \pm 158.3 \mu \mathrm{mol} / \mathrm{L}, \mathrm{p}=0.03 ; 76.4$ $\pm 114.5 \mu \mathrm{mol} / \mathrm{L}$ vs $133.4 \pm 73.7 \mu \mathrm{mol} / \mathrm{L}$ vs $342.7 \pm 318.4 \mu \mathrm{mol} /$ $\mathrm{L}, \mathrm{p}=0.002$, respectively).

\section{Clinical Courses and Outcomes}

In $47.6 \%$ (10/21) patients with bile duct injuries, outcomes improved by symptomatic treatment. In the remaining $19 \%$ (4/21) of the patients including HBDS ( $n=1)$, BM combined $\operatorname{HBDS}(\mathrm{n}=1)$ and BM $(\mathrm{n}=2)$, liver dysfunction did not improve after symptomatic treatment in conjunction with PTCD and biliary stenting. Later on, 3 patients suffered from recurrent biliary tract infections, 1 case from gall bladder stones and 2 cases from intrahepatic bile duct stones. 

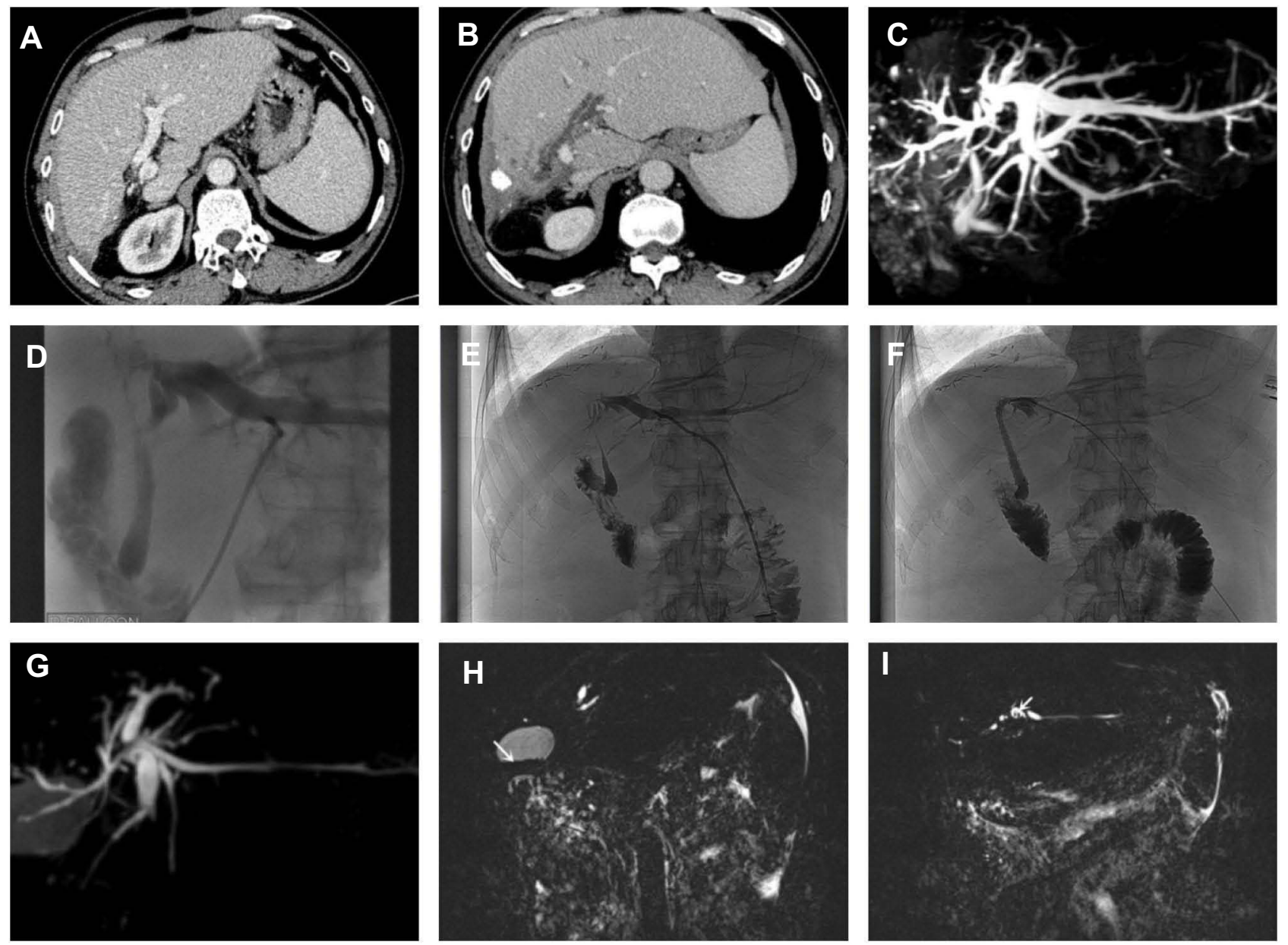

Figure 4 Male, $5 \mathrm{I}$ years old with chronic hepatitis B related cirrhosis, performed resection of right liver lobe (the $\mathrm{I}^{\text {th }}$ patient). (A) One month after surgery, abdominal enhanced-CT appeared left liver lobe compensatory hypertrophy. (B) Three months after TACE operation, upper abdominal enhanced-CT showed that the original operation of lipiodol deposition, the left intrahepatic bile duct dilatation. (C and $\mathbf{D})$ Four months after TACE, MRCP showed the left intrahepatic bile duct dilatation obviously; PTCD showed left intrahepatic bile duct dilatation and hilar bile duct stricture obviously, performed Balloon dilatation and liver external biliary drainage. (E and F) Ten months after TACE, due to obstructive jaundice hospitalized again, cholangiography displayed hilar bile duct line-like structure and left intrahepatic bile duct stick-like change; performed biliary stent implantation and postoperative imaging showed bile duct patency. (G-I) Three months after biliary stent implantation, MRCP displayed left intrahepatic bile duct atrophy changes, multiple gallstone (arrow) and the left intrahepatic bile duct stones (arrow), however these changes did not appear before TACE. Abbreviations: TACE, transcatheter arterial chemoembolization; HCC, hepatocellular carcinoma; MRCP, magnetic resonance cholangiopancreatography; PTCD, percutaneous transhepatic cholangial drainage.

In the long-term follow-up, $19 \%$ (4/21) of cases presented with recurrent HCCs. Of whom 3 cases had intrahepatic metastasis and one case had extrahepatic metastasis, and only appropriate palliative care could be given to these patients.

Because of liver failure, $14.3 \%$ (3/21) died of decompensated hepatic cirrhosis, including esophageal variceal bleeding $(\mathrm{n}=1)$, massive ascites $(\mathrm{n}=1)$ and hepatic encephalopathy $(\mathrm{n}=1)$.

\section{Discussion}

TACE has gained worldwide acceptance within the BCLC algorithm as an effective and safe treatment modality for HCC patients. It has been documented that patients with
HCC can be cured, have improved long-term survival and significantly improved quality of life after appropriate TACE treatment. However, as the use of TACE is increasing consideration must be given to the serious complications that may result. One of the most serious complications of TACE is biliary tract injury. Blood supply to the bile ducts mainly arises from the hepatic artery branches, which form a double capillary network around the bile ducts. ${ }^{31}$ More than $90 \%$ of the blood supply to $\mathrm{HCC}>1 \mathrm{~cm}$ in diameter is from the hepatic artery, with the portal vein contributing the remainder of blood supply. While performing TACE, hepatic arteries/ arterioles that supply the bile duct are likely to be embolized, and thus cause ischemic necrosis of the bile duct. 

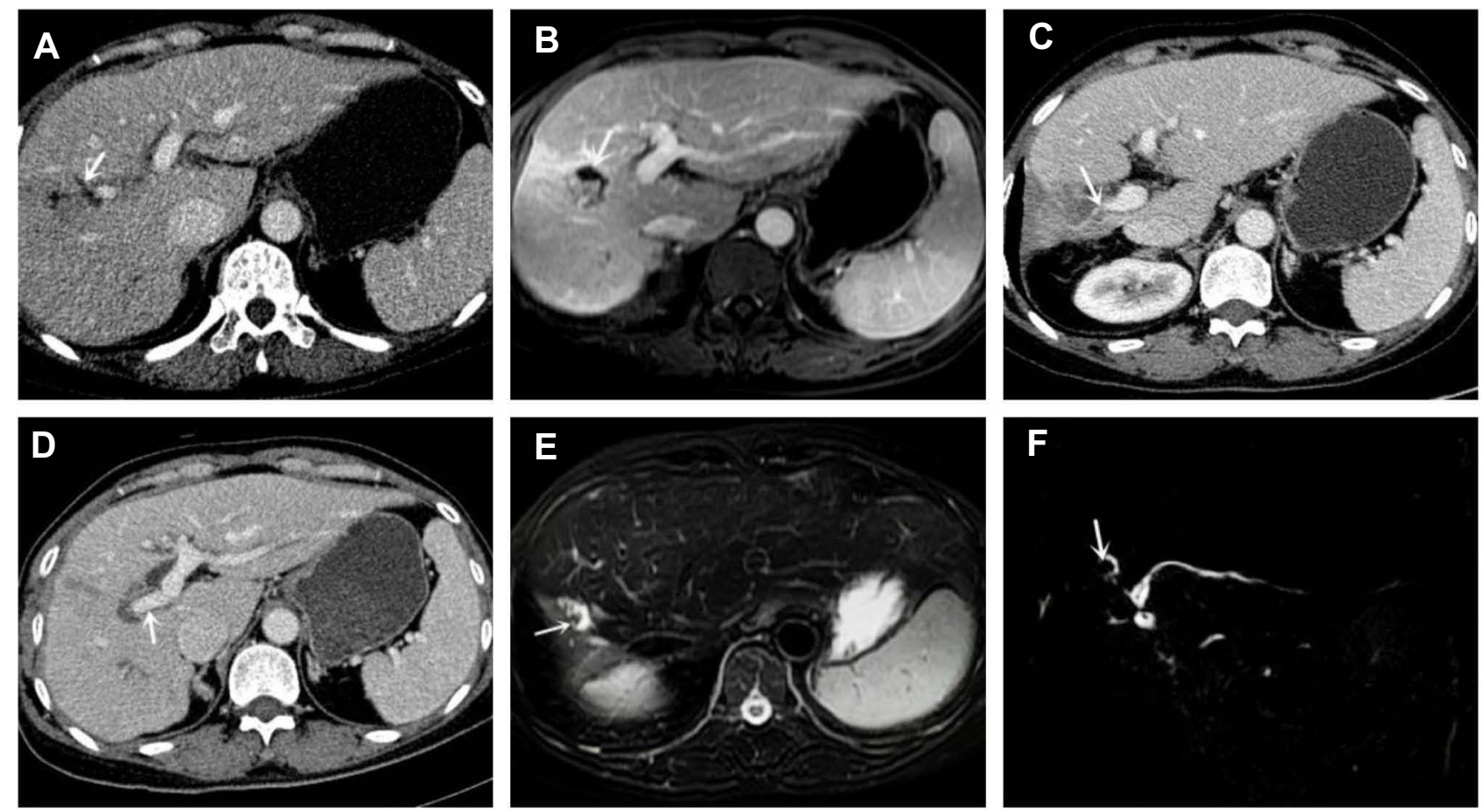

Figure 5 Female, 59 years old, after resection of right liver tumors, pathology diagnosis HCC (the $17^{\text {th }}$ patient). (A) Four months after preventive TACE operation, upper abdominal enhanced-CT appeared right intrahepatic bile ducts mild dilation (arrow) along the portal vein. (B) Ten months after TACE, contrast enhanced MRI-TIWI showed right intrahepatic bile duct irregularly low signal, and the surrounding of dilated bile ducts appeared mild enhancement (arrow), which considered as cholangitis. (C and D) Follow-up enhanced-CT showed the right branch of portal vein line-like narrowing (arrow) and right hepatic atrophy obviously compared to pre-TACE (arrow). (E and F) Follow-up MRCP showed T2WI visible inhomogeneous high signal (arrow), and right intrahepatic bile ducts appeared filling defects, which was deemed as intrahepatic bile duct stones (arrow).

Abbreviations: TACE, transcatheter arterial chemoembolization; HCC, hepatocellular carcinoma; MRCP, magnetic resonance cholangiopancreatography.

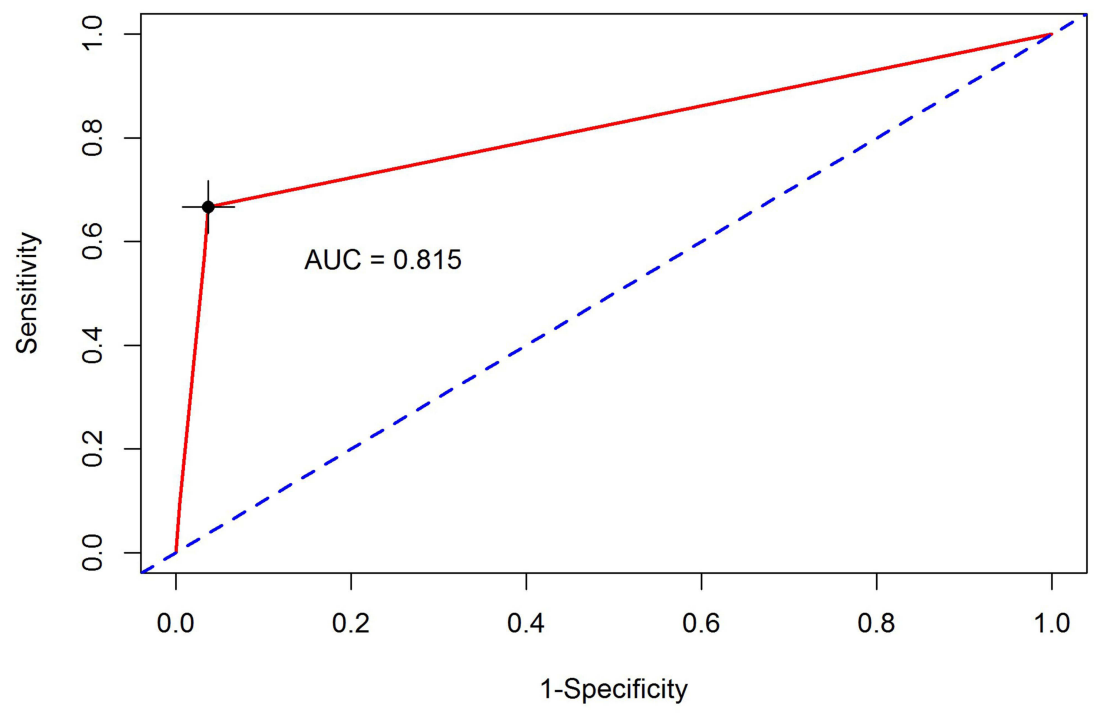

Figure 6 The area under the curve for the predictor of bile duct injury after TACE made it possible to discriminate between patients with bile duct injury and those without.

The incidence of bile duct injury is about $4.3 \%(21 /$ 483 ) in our study, which is similar to the reported incidence of $4 \%$ by Miyayama et al. ${ }^{25}$ Among the 21 cases of bile duct injuries, $83 \%$ were intrahepatic ducts vs $17 \%$ hilar ducts, demonstrating that the intrahepatic bile duct are more susceptible than the hepatic hilar bile ducts. ${ }^{32,33}$ In our study, once hepatic hilar bile duct strictures have occurred, the outcome of subsequent clinical management 
Table 4 Logistic Regression Analyses of Risk Factors of Bile Duct Injury

\begin{tabular}{|l|c|c|c|c|}
\hline Risk Factors & Coefficient & SE & $95 \%$ CI & P \\
\hline Const & -3.889 & 0.516 & $(-4.898,-2.877)$ & 0 \\
Resection of liver tumor & 1.450 & 0.527 & $(0.418,2.482)$ & 0.006 \\
Tumor-feeding artery & -1.563 & 0.638 & $(-2.813,-0.313)$ & 0.014 \\
Proximal artery & 0.914 & 0.460 & $(0.012,1.816)$ & 0.047 \\
\hline
\end{tabular}

Abbreviations: SE, standard error; $\mathrm{Cl}$, confidence interval; Proximal artery, including the proper hepatic artery, right and/or left hepatic artery.

Table 5 Risk Factors of Bile Duct Injury After TACE in 483 Patients with HCC

\begin{tabular}{|c|c|c|c|}
\hline Risk Factors & $\begin{array}{l}\text { No. of } \\
\text { Patients } \\
(n=483)\end{array}$ & $\begin{array}{l}\text { No. of Bile } \\
\text { Duct Injury } \\
(n=2 I)\end{array}$ & $\mathbf{P}$ \\
\hline $\begin{array}{l}\text { Underlying disease } \\
\text { With } \\
\text { Without }\end{array}$ & $\begin{array}{l}183 \\
300\end{array}$ & $\begin{array}{l}8(4.37 \%) \\
13(4.33 \%)\end{array}$ & 0.985 \\
\hline $\begin{array}{l}\text { Resection of liver } \\
\text { tumor } \\
\text { With } \\
\text { without }\end{array}$ & $\begin{array}{l}200 \\
283\end{array}$ & $\begin{array}{l}16(8 \%) \\
5(1.8 \%)\end{array}$ & 0.002 \\
\hline Tumor size & $4.86 \pm 3.18$ & $3.15 \pm 4.19$ & 0.076 \\
\hline $\begin{array}{l}\text { Chemotherapy drugs } \\
\text { Lipiodol dose }\end{array}$ & $7.8 \pm 3.6$ & $7.2 \pm 3.3$ & $\begin{array}{l}\text { NS } \\
0.426\end{array}$ \\
\hline $\begin{array}{l}\text { Embolization particles } \\
\text { Lipiodol } \\
\text { Gelatin sponge and } \\
\text { PVA }\end{array}$ & $\begin{array}{l}450 \\
33\end{array}$ & $\begin{array}{l}18(4 \%) \\
3(9 \%)\end{array}$ & 0.387 \\
\hline $\begin{array}{l}\text { Site of embolization } \\
\text { Tumor-feeding } \\
\text { artery } \\
\text { Proximal artery } \\
\text { Mixture }\end{array}$ & $\begin{array}{l}213 \\
152 \\
118\end{array}$ & $\begin{array}{l}3(1.4 \%) \\
I 1(7.2 \%) \\
7(2.4 \%)\end{array}$ & $P^{2}=0.69$ \\
\hline
\end{tabular}

Abbreviations: NS, not statistically significant; Underlying disease, including hypertension, diabetes and thrombotic disease; Mixture, tumor-feeding artery and proximal embolization; Proximal artery, including the proper hepatic artery, right and/or left hepatic artery; $\mathrm{P}^{\mathrm{l}}$, comparison between tumor-feeding artery and proximal artery; $\mathrm{P}^{2}$, comparison between mixture and proximal artery.

is often unsatisfactory despite additional biliary interventions with PTCD and stenting. This may be because patients with hilar bile duct strictures sustained recurrent cholangitis, stimulating fibrous tissue growth and aggravating the biliary stricture, initiating a cycle (stricturecholangitis-stricture). We also believe that inflammation of the bile duct accompanies and exacerbates bile duct injury.

Patients with IBDD usually have no obvious clinical symptoms, but this is a predictor of complications. In the group of biloma patients in our study, the incidence of intrahepatic bile duct dilatation is significantly increased, indicating intrahepatic bile duct dilatation is predictable for biloma. So, it is important for physicians to be familiar with those complications in order to better prevent and to initiate prompt optimal treatments once occurred.

In this study, the TACE protocols were similar and there were no significant differences between the dose of chemotherapeutic drugs or lipiodol in all 483 patients. In $14.3 \%(3 / 21)$ of cases where there was embolization with extra gelatin sponge and PVA particles, the onset of bile duct injury was significantly shorter than those of isolated iodized oil group. We hypothesize that when iodized oil in combination with PVA or gelatin sponge particles is injected into the tumor vasculature superfluous embolization particles are likely to reflux into non-target arterial branches in the later injection phase and thus render biliary ischemic injury. Therefore, we suspect the combination use of PVA and gelatin sponge particles may be a potential risk factor for bile duct injury, which remain to be confirmed in a large sample.

With the recent refinements in the technology of catheterization and angiography, superselective TACE done via a segmental/subsegmental approach has become the preferred treatment of choice in the majority of chemoembolization for $\mathrm{HCC}^{34,35}$ We found that there was a high consistency between the location of bile duct injury and the injection site of embolic materials. This indicates that bile duct injury may be associated with intrahepatic bile ducts ischemia, and suggests that there are specific blood vessels devoted to the plexiform supply of the biliary ducts and with complete devascularization bile duct injury could be induced. Miyayama et $\mathrm{al}^{24}$ reported in 2013, the blood supply of hepatic hilar bile ducts came mainly from the proximal portion of A1 (main supplying vessels of hepatic S1) and A4 (main supplying vessels of hepatic S4), and recommended that the $\mathrm{A} 1$ and $\mathrm{A} 4$ arteries should not be completely embolized to avoid ischemic bile duct injury. 
Table 6 Analysis of Laboratory Data of 21 Patients with Bile Duct Injury After TACE

\begin{tabular}{|c|c|c|c|c|c|}
\hline Parameter & Pre-TACE & I Week After TACE & Follow-Up & $\mathbf{P}_{\mathbf{I}}$ & $\mathbf{P}_{\mathbf{2}}$ \\
\hline $\mathrm{ALT}(\mathrm{U} / \mathrm{L})$ & $35.6 \pm 19.4$ & $|7| .| \pm| 40.8$ & $65.2 \pm 42.9$ & 0.015 & \\
\hline AST(U/L) & $38.6 \pm 28.2$ & $99.2 \pm 112.7$ & $63.67 \pm 29.3$ & 0.014 & \\
\hline$A L P(U / L)$ & $120.1 \pm 100.9$ & $|87.4 \pm 8| .8$ & $249.1 \pm 158.3$ & 0.006 & 0.03 \\
\hline GGT(U/L) & $76.4 \pm \mid 14.5$ & $133.4 \pm 73.7$ & $342.7 \pm 318.4$ & 0.003 & 0.002 \\
\hline $\operatorname{AFP}(\mathrm{ng} / \mathrm{mL})$ & $93.75 \pm 214.90$ & NA & $133.1 \pm 505.8$ & 0.435 & \\
\hline $\mathrm{TB}(\mu \mathrm{mol} / \mathrm{L})$ & $|4| \pm 5.5$. & $29.0 \pm 15.8$ & $34.3 \pm 42.1$ & 0.039 & \\
\hline $\mathrm{DBIL}(\mu \mathrm{mol} / \mathrm{L})$ & $5.1 \pm 3.5$ & $13.3 \pm 10.6$ & $19.5 \pm 29.8$ & 0.035 & \\
\hline IBIL $(\mu \mathrm{mol} / \mathrm{L})$ & $9 \pm 3.1$ & $15.7 \pm 5.9$ & $14.9 \pm 12.4$ & 0.055 & \\
\hline Albumin(g/L) & $39.3 \pm 4.7$ & $35.5 \pm 3.6$ & $38.4 \pm 4.8$ & 0.484 & \\
\hline
\end{tabular}

Abbreviations: ALT, alanine aminotransferase; AST, aspartate aminotransferase; ALP, alkaline phosphatase; GGT, gamma glutamyl transpeptidase; AFP, $\alpha$-Fetoprotein; TB, total bilirubin; DBIL, direct bilirubin; IBIL, indirect bilirubin; NA, not attained; $\mathrm{P}_{\mathrm{I}}$, Comparison between Pre-TACE and Follow-up (Paired $T$ test); $\mathrm{P}_{2}$, Comparison in PreTACE, I week after TACE and Follow-up (Nonparametric test).

Table 7 Predictors of Bile Duct Injury After TACE in 483 Patients with HCC

\begin{tabular}{|c|c|c|c|c|}
\hline Predictors & $\begin{array}{l}\text { With Bile Duct Injury } \\
\qquad(n=2 I)\end{array}$ & $\begin{array}{l}\text { Without Bile Duct Injury } \\
\qquad(n=462)\end{array}$ & $x^{2}$ & $\mathbf{P}$ \\
\hline $\begin{array}{l}\text { Imaging feature } \\
\text { With } \\
\text { Without }\end{array}$ & $\begin{array}{c}3 \\
18\end{array}$ & $\begin{array}{c}5 \\
457\end{array}$ & 21.498 & 0.000 \\
\hline $\begin{array}{l}\text { ALP } \\
\qquad 200 U / L \\
\quad \leq 200 U / L\end{array}$ & $\begin{array}{c}16 \\
5\end{array}$ & $\begin{array}{c}10 \\
452\end{array}$ & 216.116 & 0.000 \\
\hline
\end{tabular}

Note: ALP, alkaline phosphatase; Imaging feature: lipiodol deposited along the bile duct wall in one week non-enhanced CT.

Table 8 Binary Logistic Regression Analyses of Predictive Factors of Bile Duct Injury

\begin{tabular}{|c|c|c|c|c|c|c|c|}
\hline Predictors & B & S.E. & Wald & $\mathbf{P}$ & OR & \multicolumn{2}{|c|}{$95 \% \mathrm{Cl}$} \\
\hline Constant & -3.967 & 0.343 & 133.537 & 0.000 & 0.019 & & \\
\hline Imaging feature & $2.24 I$ & 1.025 & 4.777 & 0.029 & 9.402 & 1.260 & 70.138 \\
\hline ALP & 3.453 & 0.534 & 41.879 & 0.000 & 31.580 & 11.099 & 89.855 \\
\hline
\end{tabular}

Abbreviations: SE, standard error; $\mathrm{Cl}$, confidence interval; OR, odds ratio; ALP, alkaline phosphatase; Imaging feature, lipiodol deposited along the bile duct wall in one week non-enhanced CT.

It should be noted that only 14 TACEs procedures were in the proper hepatic artery territory, this was when there was a lack of tumor stain post hepatectomy, marked vascular derangement resulting from repeated prior TACEs and where super selective catheterization tumor feeder artery was not possible. Nine cases of bile duct injury happened in this scenario, 6 cases in the hepatic hilar and 3 cases in both left and right hepatic lobes. In patients with repeated TACEs, varying degree of steno-occlusive disease resulting from chemical vasculitis might prevent catheter accessibility to the segmental/subsegmental level. We find that 7.2\% (11/ 152) of patients show bile duct injury after TACE in the proximal artery embolization group, which has significant statistical significance compared to the Tumorfeeding artery embolization group $(1.4 \%, 3 / 213)$. It indicates proximal artery embolization is a risk factor for the TACE-related bile duct injury. We consider that proximal artery embolization may have resulted in infusion of an excessive dose of chemoembolic agent in nontumoral liver parenchyma, causing the bile duct ischemic injury. 
In addition, prior hepatectomy may be an additional risk factor for bile duct injury. We found that $8 \%(16 / 200)$ patients with prior hepatectomy had bile duct injury after preventive-TACE, while only $1.8 \%(5 / 283)$ of those without prior hepatectomy did, which has significant statistical significance. We speculated that after hepatectomy, the blood supply of intrahepatic bile duct system diminishes, furthermore, tumor "siphon-like" function was gone and chemotherapeutic drugs could disproportionately get into the normal liver parenchyma, increasing the probability of bile duct injury. During HCC resection, blood vessels to the bile ducts could also be compromised predisposing the bile ducts to initial ischemia and subsequent injury during preventive-TACE.

Our studies showed the average tumor diameter of 21 cases with bile duct injury was about $3.15 \pm 4.19 \mathrm{~cm}$, which was significantly smaller as compared to those of overall average tumor diameter of $4.86 \pm 3.18 \mathrm{~cm}$, but no statistical significance $(p=0.076)$. We believed that with larger tumors the vascularity is typically greater leading to a higher proportion of chemotherapeutic drug within the tumor rather than in the background parenchyma, which played a protective role. We also found in our study that the average onset of bile duct injury in patients with comorbid disease (such as diabetes, hypertension and deep vein thrombosis), was less than in those patients without comorbid disease, but did not achieve statistical significance.

Optimal management of bile duct injury occurring after TACE had not yet been established. In a few previous reports, ${ }^{36-38}$ mild dilatation of intrahepatic bile duct underwent no specific treatment except regular clinical follow-up. Biloma may be absorbed gradually without intervention. For growing biloma accompanied with jaundice, biliary drainage is required to decompress the biliary obstruction. In cases with a large biloma where PTCD is ineffective, partial liver resection may be required. Patients with hilar bile duct strictures require symptomatic treatment in a timely manner and, if necessary, supplemented with PTCD and biliary stenting. In this study, 3 of the 6 cases with hilar bile duct strictures were treated with PTCD and biliary stent placement. Liver function improved in one of these 3 cases. Sustained infection/inflammation of the biliary tract may also play an important role in the persistence and exacerbation of bile duct injury, leading to a vicious circle (stricture-cholangitis-stricture). During the long-term followup, we found portal vein branch stenosis corresponding to the site of bile duct injury and parenchymal atrophy, cholelithiasis and intrahepatic cholangiolithiasis. Hepatic hilar bile duct stricture complicated with long-term infection resulted in bile cholestasis leading to stone formation in the biliary system. Meanwhile, remarkably dilated bile ducts compressing the adjacent portal vein rendered portal vein stricture and caused ischemic necrosis and, finally, atrophy of the normal liver parenchyma. In addition, long-term retention of bile could further deteriorate liver function, ${ }^{19}$ symptomatic treatment might temporarily improve liver function, but the prognosis was often poor.

Early prediction of bile duct injury post TACE has been the subject of clinical study. Recently, Miyayama et $\mathrm{al}^{24,25}$ using cone-beam CT for selective engagement of S1 and/or S4 during TACE, was able to identify the precise microvasculature of the main hilar bile ducts and advocated that the clinical application of cone-beam CT technology might lessen the complication of biliary tract injury if more distal embolization done with a smaller microcatheter $<2 \mathrm{~F}$ could be accomplished. In our study we found that 3 patients showed lipiodol deposited along the bile duct wall in one week un-enhanced CT after repeated TACE, and that after follow-up CT, intrahepatic bile duct dilatation and biloma were appreciated in these patients. We hypothesized that the characteristic imaging findings indicates primary damage to the vascular network around the bile duct, which is an early predictor for bile duct injury. Therefore, we recommended unenhanced CT in one week post-TACE for assessment of regional lipiodol deposition and for early identification of bile duct injury. In our study, $76.2 \%(16 / 21)$ patients of bile duct injury had ALP greater than $200 \mathrm{U} / \mathrm{L}$ in one week. We speculate that the abnormally elevated ALP may indicate the early injury of bile duct, but the exact mechanism remains unclear. This speculation can be used as another research direction in the future.

\section{Study Limitation}

This article is a retrospective clinical analysis and because of small sample size the data accumulated and the conclusions have limitations in accuracy and predictability in real world clinical applications. In the study the proportion of men and women is also significantly different in these 21 patients, which reflects the different incidence of HCC in men and women. In Asians, the gender ratio of HCC is about 2.67:1. These gender differences may affect the results. In our study, most of patients had prior hepatectomy (16/21) before TACE. That will change the vascular territory of some hepatic arterial branches and exaggerate the development of the intrahepatic anastomosis. The original vascular anatomy of bile duct and the relationship between tumor location and the 
bile duct injury have been mostly changed in our cases. Finally, there is a lack of pathological confirmation of bile duct as all patients were considered surgically inoperable, we attempted to eliminate this bias as much as possible using strict inclusion and exclusion criteria.

\section{Conclusion}

Bile duct injury induced by TACE is not caused by a single factor, but rather by a variety of factors, and is closely related to ischemic injury to the blood vessels of bile ducts by resection of liver tumor, proximal artery embolization as well as by post-procedural recurrent biliary tract infections. Lipiodol deposited along the bile duct wall and immediate rapid rise of ALP $>200 \mathrm{U} / \mathrm{L}$ in one week after TACE can predict bile duct injury and early interventions may prevent the occurrence of serious complications. These factors should all be considered when assessing patients prior to and on follow up post TACE procedures. A prospective study of TACE-induced bile duct injury is needed to establish other possible factors predisposing to bile duct ischemia.

\section{Acknowledgments}

We gratefully acknowledge the financial support by of Basic public welfare research program of Zhejiang Province of China (LGH20H180012), Science and Technology program of Jinhua Science and Technology Bureau(2019-4-129) and foundation of Zhejiang Education Department(Y201839779).

\section{Disclosure}

The authors who have participated in this study declared that they do not have a conflict of interest with respect to this manuscript.

\section{References}

1. Bray F, Ferlay J, Soerjomataram I, et al. Global cancer statistics 2018: GLOBOCAN estimates of incidence and mortality worldwide for 36 cancers in 185 countries. CA Cancer J Clin. 2018;68(6):394-424. doi: $10.3322 /$ caac. 21492 .

2. Takayasu K, Arai S, Ikai I, et al. Prospective cohort study of transarterial chemoembolization for unresectable hepatocellular carcinoma in 8510 patients. Gastroenterology. 2006;131(2):461-469. doi:10.1053/j. gastro.2006.05.021.

3. Zhou J, Sun HC, Wang Z, et al. Guidelines for the diagnosis and treatment of Hepatocellular Carcinoma (2019 Edition). Liver Cancer. 2020;9(6):682-720. doi:10.1159/000509424.

4. Lo CM, Ngan H, Tso WK, et al. Randomized controlled trial of transarterial lipiodol chemoembolization for unresectable hepatocellular carcinoma. Hepatology. 2002;35(5):1164-1171. doi:10.1053/ jhep.2002.33156.
5. Makary MS, Khandpur U, Cloyd JM, et al. Locoregional therapy approaches for Hepatocellular carcinoma: recent advances and management strategies. Cancers. 2020;12(7):1914. doi:10.3390/ cancers 12071914.

6. Varela M, Real MI, Burrell M, et al. Chemoembolization of hepatocellular carcinoma with drug eluting beads: efficacy and doxorubicin pharmacokinetics. J Hepatol. 2007;46(3):474-481. doi:10.1016/j. jhep.2006.10.020.

7. Gupta S, Johnson MM, Murthy R, et al. Hepatic arterial embolization and chemoembolization for the treatment of patients with metastatic neuroendocrine tumors: variables affecting response rates and survival. Cancer. 2005;104(8):1590-1602. doi:10.1002/cncr.21389.

8. Sueyoshi E, Hayashida T, Sakamoto I, et al. Vascular complications of hepatic artery after transcatheter arterial chemoembolization in patients with hepatocellular carcinoma. Am J Roentgenol. 2010;195(1):245-251. doi:10.2214/AJR.08.2301.

9. Chung JW, Park JH, Han JK, et al. Hepatic tumors: predisposing factors for complications of transcatheter oily chemoembolization. Radiology. 1996;198(1):33-40. doi:10.1148/radiology.198.1.8539401.

10. Tarazov PG, Polysalov VN, Prozorovskij KV, et al. Ischemic complications of transcatheter arterial chemoembolization in liver malignancies. Acta Radiologica. 2000;41(2):156-160. doi:10.1080/ 028418500127344966 .

11. Kim HK, Chung Y-H, Song B-C, et al. Ischemic bile duct injury as a serious complication after transarterial chemoembolization in patients with hepatocellular carcinoma. J Clin Gastroenterol. 2001;32(5):423-427. doi:10.1097/00004836-200105000-00013

12. Komatsu M, Fujii T, Goto T, et al. Giant hepatic biloma following transcatheter oily chemoembolization in a patient with hepatic metastases from malignant pheochromocytoma. Internal Med. 1998;37 (12):1034-1038. doi:10.2169/internalmedicine.37.1034.

13. Pua U. Transarterial chemoembolization induced main duct stricture. Clin Gastroenterol Hepatol. 2011;9(12):A22. doi:10.1016/j. cgh.2011.06.025.

14. Kondo Y, Shiina S, Tateishi R, et al. Intrahepatic bile duct dilatation after percutaneous radiofrequency ablation for hepatocellular carcinoma: impact on patient's prognosis. Liver Int. 2011;31(2):197-205. doi:10.1111/j.1478-3231.2010.02415.x.

15. Bhagat N, Reyes DK, Lin M, et al. Phase II study of chemoembolization with drug-eluting beads in patients with hepatic neuroendocrine metastases: high incidence of biliary injury. Cardiovasc Intervent Radiol. 2013;36(2):449-459. doi:10.1007/s00270-012-0424-y.

16. EASL-EORTC. Clinical practice guidelines. Management of hepatocellular carcinoma. J Hepatol. 2012;56(4):908-943. doi:10.1016/j. jhep.2011.12.001.

17. Llovet JM, Real MI, Montana X, et al. Arterial embolisation or chemoembolization versus symptomatic treatment in patients with unresectable hepatocellular carcinoma: a randomized controlled trial. Lancet. 2002;359(9319):1734-1739. doi:10.1016/S0140-6736(02)08649-X.

18. Chung J, Yu JS, Chung JJ, et al. Hemodynamic events and localised parenchymal changes following transcatheter arterial chemoembolization for hepatic malignancy: interpretation of imaging findings. $\mathrm{Br}$ J Radiol. 2010;83(985):71-81. doi:10.1259/bjr/82377365.

19. Yu JS, Kim KW, Jeong MG, et al. Predisposing factors of bile duct injury after transcatheter arterial chemoembolization (TACE) for hepatic malignancy. Cardiovasc Intervent Radiol. 2002;25 (4):270-274. doi:10.1007/s00270-001-0049-z.

20. Yu JS, Kim KW, Park MS, et al. Bile duct injuries leading to portal vein obliteration after transcatheter arterial chemoembolization in the liver: CT findings and initial observations. Radiology. 2001;221 (2):429-436. doi:10.1148/radiol.2212010339.

21. Bang BW, Lee DH, Jeong $\mathrm{S}$, et al. Ischemic biliary stricture developed after repeated transcatheter arterial chemoembolization diagnosed by percutaneous transhepatic cholangioscopy in a patient with hepatocellular carcinoma. Gastrointest Endosc. 2008;68(6):1224-1226. doi:10.1016/j. gie.2008.03.004. 
22. Makuuchi M, Sukigara M, Mori T, et al. Bile duct necrosis: complication of transcatheter hepatic arterial embolization. Radiology. 1985;156(2):331-334. doi:10.1148/radiology.156.2.2989972.

23. Kobayashi S, Nakanuma Y, Terada T, Matsui O. Postmortem survey of bile duct necrosis and biloma in hepatocellular carcinoma after transcatheter arterial chemoembolization therapy: relevance to microvascular damages of peribiliary capillary plexus. Am J Gastroenterol. 1993;88(9):1410-1415.

24. Miyayama S, Yamashiro M, Hashimoto M, et al. Blood supply of the main bile duct from the caudate artery and medial subsegmental artery of the hepatic artery: evaluation using images obtained during transcatheter arterial chemoembolization for hepatocellular carcinoma. Hepatol Res. 2013;43(11):1175-1181. doi:10.1111/ hepr.12071.

25. Miyayama S, Yamashiro M, Okuda M, et al. Main bile duct stricture occurring after transcatheter arterial chemoembolization for hepatocellular carcinoma. Cardiovasc Intervent Radiol. 2010;33 (6):1168-1179. doi:10.1007/s00270-009-9781-6.

26. Guiu B, Deschamps F, Aho S, et al. Liver/biliary injuries following chemoembolization of endocrine tumours and hepatocellular carcinoma: lipiodol vs. drug-eluting beads. $J$ Hepatol. 2012;56 (3):609-617. doi:10.1016/j.jhep.2011.09.012.

27. Spina JC, Ulla M, Yeyati EL, et al. MDCT findings after hepatic chemoembolization with DC-beads: what the radiologist needs to know. Abdom Imaging. 2013;38(4):778-784. doi:10.1007/s00261012-9963-6.

28. Kobayashi S, Kozaka K, Gabata T, et al. Pathophysiology and imaging findings of bile duct necrosis: a rare but serious complication of transarterial therapy for liver tumors. Cancers. 2020;12(9):2596. doi:10.3390/cancers12092596.

29. Alabdulghani F, Healy GM, Cantwell CP, et al. Radiological findings in ischaemic cholangiopathy. Clin Radiol. 2020;75(3):161-168. doi:10.1016/j.crad.2019.10.017.
30. Cui J, de Klerk N, Abramson M, et al. Fractional polynomials and model selection in generalized estimating equations analysis, with an application to a longitudinal epidemiologic study in Australia. Am J Epidemiol. 2009;169(1):113-121. doi:10.1093/aje/kwn292.

31. Chen W, Ying D, Liu Z, He Z. Analysis of the arterial supply of the extrahepatic bile ducts and its clinical significance. Clin Anatomy. 1999;12(4):245-249. doi:10.1002/(SICI)1098-2353(1999)12:4<245:: AID-CA2>3.0.CO;2-W

32. Gunji H, Cho A, Tohma T, et al. The blood supply of the hilar bile duct and its relationship to the communicating arcade located between the right and left hepatic arteries. Am J Surg. 2006;192 (3):276-280. doi:10.1016/j.amjsurg.2006.01.046.

33. Strasberg SM, Helton WS. An analytical review of vasculobiliary injury in laparoscopic and open cholecystectomy. HPB (Oxford). 2011;13(1):1-14. doi:10.1111/j.1477-2574.2010.00225.x.

34. Lang E, Brown C. Colorectal metastases to the liver: selective chemoembolization. Radiology. 1993;189(2):417-422. doi:10.1148/ radiology.189.2.8210369.

35. Therasse E, Breittmayer F, Roche A, et al. Transcatheter chemoembolization of progressive carcinoid liver metastasis. Radiology. 1993;189(2):541-547. doi:10.1148/radiology.189.2.7692465.

36. Sakamoto I, Iwanaga S, Nagaoki K, et al. Intrahepatic biloma formation (bile duct necrosis) after transcatheter arterial chemoembolization. Am J Roentgenol. 2003;181(1):79-87. doi:10.2214/ajr.181.1.1810079.

37. Boulin M, Adam H, Guiu B, et al. Predictive factors of transarterial chemoembolization toxicity in unresectable hepatocellular carcinoma. Dig Liver Dis. 2014;46(4):358-362. doi:10.1016/j. dld.2013.12.012.

38. Thompson CM, Saad NE, Quazi RR, et al. Management of iatrogenic bile duct injuries: role of the interventional radiologist. Radiographics. 2013;33(1):117-134. doi:10.1148/rg.331125044.

\section{Publish your work in this journal}

Cancer Management and Research is an international, peer-reviewed open access journal focusing on cancer research and the optimal use of preventative and integrated treatment interventions to achieve improved outcomes, enhanced survival and quality of life for the cancer patient.
The manuscript management system is completely online and includes a very quick and fair peer-review system, which is all easy to use. Visit http://www.dovepress.com/testimonials.php to read real quotes from published authors. 